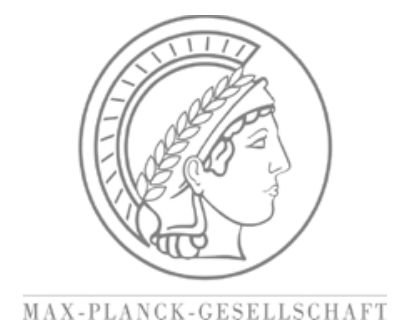

\# 1103

The Dynamics of Consumer Behavior and the Transition to Sustainable Consumption Patterns

by

\title{
Ulrich Witt
}

The Papers on Economics and Evolution are edited by the Evolutionary Economics Group, MPI Jena. For editorial correspondence, please contact: evopapers@econ.mpg.de

ISSN 1430-4716
Max Planck Institute of Economics Evolutionary Economics Group Kahlaische Str. 10 07745 Jena, Germany Fax: ++49-3641-686868

(C) by the author 


\title{
The Dynamics of Consumer Behavior and the Transition to Sustainable Consumption Patterns
}

\author{
Ulrich Witt \\ Max Planck Institute of Economics, Jena, Germany \\ witt@econ.mpg.de
}

abstract

Strong growth in disposable income has driven, and is still driving, consumption to unprecedented, but not sustainable levels. To explain the dynamic interplay of needs, need satisfaction, and innovation underlying that growth a behavioral theory of consumption is suggested and discussed with respect to its implications for making a transition to more sustainable patterns of consumer behavior.

Keywords: consumption, growth, sustainability, satiation, innovation, welfare

JEL-Code: A 13, B52, D01, D03, D11, Q50, Q56 


\section{Introduction}

In the developed countries, consumption drives much of the environmental stress, waste, degradation, and resource exhaustion directly or indirectly qua the production of the goods and services demanded. This situation is the result of a century long process fueled by the unprecedented growth of real per capita income. When discussing options for making a transition to consumption patterns with less harmful consequences it seems useful, therefore, to ponder how consumers have come to respond to a situation of relative affluence. Consumption expenditures have followed closely the dramatic increases of per capita income. In the U.S., for example, consumer spending has been rising over just one century in real terms by roughly the factor five (U.S. Bureau of Labor Statistics, Report 991, 2006) - yes, calculated in prices of 2002, the budget an average American could spend in 1901 was only little more than $20 \%$ of the budget of 2002! The drastic expansion has not equally taken place in all consumption categories. In some of them income elasticity has been greater than one, in others smaller than one, and in yet others consumption comes close to a state reflecting saturation (see, e.g., Lebergott 1993). To simply assume that consumers are insatiable - as in canonical economics in order to ensure unique solutions for the utility maximization calculus - is therefore not very helpful both for explaining the uneven growth of consumption categories and for inquiring into how a transition to more sustainable consumption patterns can be made.

\section{The Growth of Consumption and its Reasons}

To explain what is going on it is necessary to account for the highly complex motivations underlying consumer behavior (the revealed, but unexplained preferences of textbook economics). These motivations are likely to change when the ability to spend increases with rising income. As discussed in more detail elsewhere (Witt 2001), this fundamental conjecture can be substantiated as a dynamics of learning and satiation. For this purpose, a set of hypotheses is required which specify what is left open in canonical economics: the answer to the question where utility comes from. The necessary extension can take recourse to a few general concepts as follows. From behavioral science it is known that, if an organism is deprived of something, a motivation builds up to take an action that is able to (temporarily) reduce deprivation. Let us call that what is deprived a "need". ${ }^{1}$ Among these needs are those for water, sleep, food, body heat, shelter, pain relief, physical activity, sex, affection, social recognition and status, sensory and cognitive arousal,

1 Since the reduction of deprivation is a reinforcing event in the sense of the theory of instrumental or operant conditioning, the concept of needs, as used here, coincides with what is called primary reinforcers in behavioral science (see, e.g., Herrnstein 1990, Staddon and Cerutti 2003). 
and consistency of self-image which are quite universally shared among humans (and not only humans). The partly cognitively mediated satisfaction of these needs is what, in the economic terminology, generates utility. ${ }^{2}$

The crucial insight becoming feasible by this extension is how these needs differ with regard to their satiability when consumption is increased. The intake of food or something to drink, for example, is subject to homoeostatic controls so that normally the motivation for additional consumption vanishes as the satiation level - a certain average quantity per unit of time - is approached. With rising income, it is therefore likely that the growth in the intake of food and drinks is sooner or later stagnating, not necessarily so, however, the corresponding expenditures. The food industry experiences the stagnation (corresponding to an income elasticity smaller than one) as market saturation. And as all businesses in saturated markets facing stiffening price competition and declining profits, suppliers have strong incentives to create extra demand by innovative products.

Since for the entire food industry the satiation level in calories is an increasingly binding constraint, additional expenditures can only be elicited in two ways (ignoring for the moment an increase in waste of food). The producers can either upgrade the quality resulting in a higher price per calorie, provided consumers honor the quality improvement; or they can reduce the satiating content - in this case: of calories - per product. An example of the first innovation strategy is the large scale import of exotic produce from all over the world (inducing major long haul transport activities), finding acceptance among consumers for reasons to be explained shortly. An instance of the second strategy are product innovations that allow to enjoy the rewarding experience of eating something tasty without coming nearer to the physiological satiation level, e.g. food stuffs made with low-calorie, artificial sweeteners. Satiation is postponed and so is market saturation (see Ruprecht 2005). Diet Coke is a prominent example.

Not all needs are as easily satiated as those for food and drinks, however. It can therefore be expected that, with rising income, consumer expenditures are increasingly shifting in the direction of goods that serve the less easily satiable needs. This has been, and will continue to be, reflected in the differences in the income elasticities of the expenditure categories empirically recorded by consumer surveys. Consider, e.g., the need for social recognition and status.

2 Note that the quantities of water, sleep, food, etc. cannot simply be plugged in for the usual placeholder variables $x_{1}, \ldots, x_{n}$ in a static utility function $u=u\left(x_{1}, \ldots, x_{n}\right)$ since they are consumed on very different time scales with a limited and varying substitutability. The relevant analytic representation would be a program instead of a function, and it is doubtful whether a dynamic optimization of the program in its entirety, if feasible at all, would be relevant for actually observable behavior. 
Consumption items able to signal the desired status by distinguishing oneself from others can serve the satisfaction of this need. Yet, with rising average income, lower income groups can also acquire such consumption items so that the status-distinguishing character goes lost. To avoid being deprived of one's relative status, other, and usually more expensive, goods need to be consumed. A level of satiation can, if at all, only be upheld by continuously rising the expenditures on status goods - an unstable situation like in an arms race (Hirsch 1978, Frank 2007) .

Another example in which a lasting satiation is difficult to attain and consumption can therefore expand without average deprivation being reduced significantly is the need for sensory and cognitive arousal. The reason arises here from a kind of stupefaction effect that calls for making ever stronger stimuli available for serving the need (Scitovsky 1981). With growing income the satiation level is continually rising and so is the corresponding consumption. The instability can be expected to be reflected in the expenditures on entertainment, tourism, particularly long haul and adventure tourism, and the services of mass media - expenditure categories that have been growing much faster with rising income than average consumption expenditures and are likely to continue to do so (see Report 991, 2006 by the U.S. Bureau of Labor Statistics).

If one and the same consumption good appeals to several needs simultaneously, and if the quantities at which the satiation levels of the needs are reached differ, a unique satiation level is not defined - the case of "combination goods". With increasing consumption of such goods the satiation levels of one need after the other are then reached. However, a (successively reduced) motivation to further expand consumption continues to exist up to the satiation level of the least easily satiated need. For producers facing an increasingly saturated market, innovation by means of creating combination goods is therefore an attractive strategy: adding features to their products that appeal to additional needs that are less easily satiable than the ones their products originally serve. Product differentiation strategies aiming in this direction are, for instance, the adding of symbols that can be used to signal status or a particular group identity like in apparel, foot ware, bags, etc. (see Witt 2010). A further example is the adding of features appealing to sensory and cognitive arousal as in the case of exotic food mentioned above.

An important aspect of any attempt to substantiate the motivational underpinnings of consumer behavior is the question of how preferences (or the ways utility is obtained) are changing over time. Since in the substantiation outlined above the need concept coincides with the notion of reinforcement, an important secondary dynamics of preference change can be traced back to the effects of conditioned reinforcement or conditioning learning on consumer behavior. In this kind of learning the following happens (see Leslie 1996). Consider the rewarding experience of an action or event reducing deprivation (i.e. satisfying a need as defined above). If this experience coincides repeatedly with actions or events that are initially experienced as neutral an association is learnt by which the originally neutral action eventually triggers a rewarding 
experience by virtue of the learnt association. A conditioned reinforcers emerges or, to refer to the corresponding consumption motivation, an "acquired want". (Unlike the widely interpersonally shared needs that were mentioned, the emerging structure of acquired wants is of a more idiosyncratic nature, though there are also group-specific influences from the particular cultural environment in which conditioning takes place.)

Imagine, for example, that it frequently happens that someone takes a meal, when hungry, in a particular setting of scenic architecture, furniture, tableware, table music etc. Even though such a special environment may initially be a neutral experience, by the association that is learnt, the scenic architecture, furniture, tableware, table music etc. may become a rewarding experience in its own right - a conditioned reinforcer. Accordingly, enjoying such aesthetic attributes can become an own motivation for consumption, a motivation - this is the clue - that often contributes much more to rising expenditures than the motivation to eat on which it was originally conditioned.

The motivation forces underlying consumer behavior as discussed so far are, of course, often mediated by cognitive deliberation. By cognitive construction of means-ends relationships consumers assess possible actions with respect to their instrumental value for attaining need satisfaction. This assessment can lead to deviations from behavior that reinforcement contingencies alone would predict. This is particularly true where the commodities consumed have "tool" character, i.e. where they provide "services", and where it is these services, not the commodities themselves, that reduce deprivation (e.g. clothes whose service is to contribute to maintain body temperature). The point here is that the motivation to purchase such tools and the motivation to use their services are two different things. Accordingly, satiation occurs, if at all, in the amount of the services consumed per unit of time. (The service of one dress, say, would suffice to feel warm enough.) The number of tools purchased are not subject to direct satiation. A motivation to buy additional ones can therefore still be present when, in terms of their services, a capacity sufficient for satiating the underlying need(s) has already been reached. The reason is that this motivation is cognitively mediated. It depends on how consumers perceive the instrumental relationship between the tools and their services.

If the producers can give reasons that convince consumers of an additional instrumental value of new or differentiated products, a motivation for multiple purchases can be induced where the original service(s) offered by those products would not motivate such purchases. Reasons may, e.g., be convenience or redundancy arguments regarding multiple availability for different purposes or at different places, or specialized functionality reasons. Consider the case of foot ware. One pair of shoes (a "tool" providing pain protection and contributing to keeping body temperature as "services") would, in principle, be - and for most of human cultural history has been - sufficient to reach the satiation level with respect to the services. With the introduction 
of functionally differentiated shoes - serving casual home use, representative purposes, working requirements, leisure activities (walking, hiking, tennis, etc.), and fashion-based status-signaling - sufficiently convincing reasons have been provided for raising multiple purchases of foot ware to ever higher levels. Since only one pair of shoes can be worn at the same time, this means that for each single pair of shoes the average rate of using its services decreases if the utilization period is not proportionately prolonged. Precisely this is, of course, often prevented by changes in fashion (Chai, Earl, and Potts 2007) and aging processes in materials.

Needless to say, multiple purchases mean additional materials, energy, and space being used (up). Furthermore, cognitive activity also implies motivational forces of its own as, for example, consistency of self-image (Dunning 2007) and the pervasive need for high self-esteem (Gollwitzer and Kirchhof 1998). These motivations can trigger substantial consumer expenditures and seem to do so the more, the higher per capita income becomes (a striking example is the soaring growth of expenditures on cosmetic surgery). Self-image and self-esteem are both contingent on social norms which are not necessarily stable. If everybody is striving to spend enough to be better than average in satisfying the norm, an inherently unstable winding-up of the norm is set in motion.

\section{Implications for Societal Transition}

Since Bentham's inception of utilitarianism, economists have been inspired by the twin idea of explaining economic behavior and assessing its moral legitimacy. Today the latter idea only occurs in the abstract disguise of welfare theory. Once the black box of subjective preferences is opened, however, and the underlying motivational forces are diagnosed as outlined here, welfare theory becomes a debatable basis for assessing what changes in consumption would seem warranted. Welfare economics has no answer to the question of what stage of preference learning should be taken as a basis for assessing whether there are any welfare gains; and it is silent on whether the different motivations underlying consumption can claim different normative legitimacy (see Binder 2010).

True, the multiplication of per capita disposable income has enabled not only the upper strata of society but also the masses to enjoy what by historical standards is a "good" life. Nonetheless, a judgment on what is a still better life cannot be made independent of the level of income already reached. Once disposable income allows to remove deprivation in the pressing human needs, motivational mechanisms take over in guiding consumer behavior that are less innocent with respect to their environmental impact. What consumers then enjoy as pleasures, to use the utilitarian diction, are largely learnt pleasures, and where the pleasures would, in principle, seem satiable with the income level reached, cognitive motives are usually learnt so as 
to enjoy ways of further income spending that avoid satiation. Yet there is a notable asymmetry. Had there been no opportunity to experience all the new consumption possibilities there would have been no opportunity to learn to appreciate them - and no sense of missing something. Once all the experiences have been made, though, foregoing the learnt pleasures would be felt as a harsh privation. In view of the severe environmental degradation and resource exhaustion caused by modern consumption patterns this asymmetry can be argued to have moral relevance when it comes to assessing what transitions are to be made for reaching more sustainable consumption patterns.

However, one of the puzzling questions in the transition debate is: who has the power and motivation to act to change consumer behavior - the consumers themselves, the producers, the government? It would be an illusion to believe that, in an economy committed to growth, producers could escape from the spiral of saturated markets triggering innovations that aim at creating additional demand that sooner or later is satiated too. It would be illusionary to assume that producers facing increasing saturation in the rich economies would not seek, or even press for, the opportunity to expand into non-saturated markets of the developing economies advertising and propagating the devastating, resource-intensive consumption patterns there to hundreds of millions of future consumers. And it would be totally illusionary, if not an expression of dual morality (see Chang 2003), to hope that these new, inexperienced consumers would be the ones who abstain from adopting the advertised life style while consumers in the developed countries seem unable to emancipate themselves from their drifting motivations.

It is difficult to imagine therefore that a transition can come about without regulations and suitable discriminatory taxation being invoked on the innovation and exportation process. Several of the necessary measures have been discussed for quite some while, particularly those focusing on product characteristics and features of the production process. Among them are regulations forcing a "de-materialization" strategy (Schmidt-Bleek 1994) which, to the extent to which the resource savings can be privately internalized, amounts to little more than enforcing corresponding conventions. Stricter regulations here or with respect to energy conversation in, and energy efficiency of, consumer goods and corresponding emission standards need to be supplemented by policies avoiding rebound effects (see van den Bergh 2011). Also the reduction of incentives for, or even taxation of, mass production in agriculture and food processing, should be mentioned here as measures directly impacting on consumer behavior. If these measures were successfully implemented, the further expansion of demand would develop significantly less environmental harm - provided the costs of these measures in terms of international competitiveness and domestic economic growth still allow any further expansion.

What has much less been discussed are regulations and taxes that try to induce shifts in consumer expenditures themselves, particularly a selective and progressively shaped taxation of 
consumption. Much environmental harm could be prevented if consumers substituted the consumption of products and resource-intensive services (like those of the tourism industry-one of the fastest growing industries world wide) by less resource-intensive products and services. The latter kind of service like care, personal assistance, the arts, education, research, law enforcement, defense, and others tend to be labor-intensive. Under the influence of rising wages and, hence, rising costs of these services, what actually currently happens is the opposite tendency: substituting away from labor-intensive services. This is equally obvious where the supply of these services is or can privately be organized as for example in the case of care, personal assistance, the arts, or education as it is in the cases where the supply is publicly provided as a public or merit good like research, law enforcement, or defense.

Perhaps surprisingly, a good deal of the transition that seems to be necessary to come closer to sustainable consumption patterns thus requires reverting processes that are under way as a result of a declining willingness to pay for the increasing relative costs of labor-intensive services. Ultimately, the substitution is driven by the secularly declining prices of natural resources relative to wages that makes resource-intensive products and services relatively cheaper. But it is precisely this falling price ratio that is not sustainable - calling for correction more generally or, where this is not possible, more specifically by regulations and discriminating taxes on resourceintensive products and services.

\section{Conclusions}

The question remains, of course, who is going to act and with what motivation. Where should the majority votes for these measures in democracies come from? All that can probably be hoped for is that a public discourse in the richest economies gains momentum that acknowledges the moral relevance of the notable asymmetric effect which is exerted on our well-being by what we learn to consume. Putting the environmental disturbances of consumption in perspective with the drifting motivations underlying consumption, sovereign voters may show more insight to form the necessary majorities in the political arena where sovereign consumers hesitate to abstain from what they have been conditioned to want. In order to get the public discourse going it is not helpful to treat consumer motivation as a taboo (as some interpretations of consumer sovereignty do; see Norton, Costanza and Bishop 1998 for a criticism). Endowed with reason, we are all able to reflect whether certain consumption patterns are worth it, if we become aware of their true costs. Inviting people to reflect on their mind set in this regard is not paternalism. 


\section{References}

Binder, M. (2010),

Elements of an Evolutionary Theory of Welfare, London: Routledge.

Chai, A., Earl, P., Potts, J. (2007),

Fashion, Growth, and Welfare: An Evolutionary Approach, in: M. Bianchi (ed.), The Evolution of Consumption: Theories and Practices, Advances in Austrian Economics, Vol. 10, Amsterdam: Elsevier, 231-248.

Chang, H.-J. (2003),

Kicking Away the Ladder: Development Strategy in Historical Perspective, London: Anthem Press.

Dunning, D. (2007),

Self-Image Motives and Consumer Behavior: How Sacrosanct Self-Beliefs Sway Preferences in the Marketplace, Journal of Consumer Psychology, 17(4), 237-249.

Frank, R.H. (2007),

Does Context Matter More for Some Goods Than Others? in: M. Bianchi (ed.), The Evolution of Consumption: Theories and Practices, Advances in Austrian Economics, Vol. 10, Amsterdam: Elsevier, 231-248.

Gollwitzer, P.M. and Kirchhof, O. (1998),

The Willful Pursuit of Identity, in: J. Heckhausen, C.S. Dweck (eds.), Motivation and Selfregulation Across the Life Span, Cambridge: Cambridge University Press.

Herrnstein, R.J. (1990),

"Behavior, Reinforcement and Utility", Psychological Science, 1: 217-224.

Hirsch, F. (1978)

Social Limits to Growth, Cambridge, MA: Harvard University Press.

Lebergott, S. (1993),

Pursuing Happiness - American Consumers in the Twentieth Century, Princeton: Princeton University Press.

Leslie J.C. (1996)

Principles of Behavioral Analysis, Amsterdam: Harwood Academic Publishers.

Norton, B., Costanza, R., Bishop R.C. (1998),

"The Evolution of Preferences - Why 'Sovereign' Preferences May Not Lead to Sustainable Policies and What to Do About It", Ecological Economics, 24, 193-211.

Ruprecht, W. (2005),

"The Historical Development of the Consumption of Sweeteners - A Learning Approach", Journal of Evolutionary Economics, Vol. 15, 247-272.

Schmidt-Bleek, F. (1994),

“How to Reach a Sustainable Economy?" Wuppertal Papers, 24, Wuppertal: Wuppertal Institute for Climate, Environment and Energy. 
Scitovsky, T. (1981),

"The Desire for Excitement", Kyklos, 34, 3-13

Staddon, J.E.R. and Cerutti, D.T. (2003),

"Operant Conditioning", Annual Review of Psychology, 54, 115-144.

van den Bergh, J.C.J.M. (2011),

"Energy Conversation More Effective with Rebound Policy", Environmental and Resource Economics, 48 (1), 43-58.

Witt, U. (2001),

"Learning to Consume - A Theory of Wants and the Growth of Demand", Journal of Evolutionary Economics, Vol. 11, 23-36.

Witt, U. (2010),

"Symbolic Consumption and the Social Construction of Product Characteristics", Structural Change and Economic Dynamics, 21, 17-25. 